\title{
LANTHANIDE-DOPED $\mathrm{Y}_{2} \mathrm{O}_{3}-$ THE PHOTOLUMINESCENT AND RADIOLUMINESCENT PROPERTIES OF SOL-GEL PREPARED SAMPLES
}

\author{
${ }^{\#}$ K. RUBEŠOVÁ*, T. THOŘ*, V. JAKEŠ*, D. MIKOLÁŠOVÁ*, J. MAIXNER**, O. JANKOVSKÝ*, \\ J. CAJZL*, L. NÁDHERNÝ*, A. BEITLEROVÁ***, M. NIKL*** \\ *Department of Inorganic Chemistry, University of Chemistry and Technology, Technická 5, Prague 6, 16628 , Czech Republic \\ **Central Laboratories, University of Chemistry and Technology, Technická 5, Prague 6, 166 28, Czech Republic \\ ***Institute of Physics, the Academy of Sciences of the Czech Republic, Cukrovarnická 10, 162 00, Prague 8, Czech Republic
}

${ }^{\#}$ E-mail: rubesovk@vscht.cz

Submitted July 20, 2018; accepted August 24, 2018

\begin{abstract}
Keywords: Yttrium oxide, Europium, Dysprosium, Terbium, Praseodymium, Sol-gel, XRD, Photoluminescence, Radioluminescence

Rare earth-metals sesquioxides (including $\mathrm{Y}_{2} \mathrm{O}_{3}$ ) represent a group of materials with extraordinary properties applicable in various technologies. However, one of the special properties - high melting temperature - hinders the wide application of monocrystalline materials. Therefore, it is still important to test other synthesis methods even for relatively well-known materials and even in the form of bulk ceramics. Here, we present the series of lanthanide-doped $\mathrm{Y}_{2} \mathrm{O}_{3}\left(\mathrm{Eu}^{3+}, \mathrm{Pr}^{3+}, \mathrm{Dy}^{3+}\right.$ and $\mathrm{Tb}^{3+}$ being the dopants) prepared by a Pechini-based method. We demonstrate that this method produces single-phase material with luminescence properties comparable to those of single crystals as proved by the photoluminescence and radioluminescence excited by UV light and X-rays, respectively.
\end{abstract}

\section{INTRODUCTION}

Sesquioxides of $\mathrm{A}_{2} \mathrm{O}_{3}$ stoichiometry are among the most studied materials with a broad range of applications [1-4]. In particular, the sesquioxides of $\mathrm{Y}, \mathrm{Sc}$ and lanthanide metals (together called rare-earth (RE) metals sesquioxides) have been studied for their optical or catalysing properties [5]. Apart from their wide use in the coloration of glasses and ceramics, these sesquioxides have been applied either as phosphors in sensors, display screens and fluorescent lamps, or as matrices in solid state lasers $[6,7]$.

The stability and durability of the RE sesquioxides are related to their high melting temperature, mostly exceeding $2400^{\circ} \mathrm{C}$. Due to their high density and effective atomic number, some sesquioxides have high stopping power for high-energy radiation which makes them adepts for use as scintillation detectors. For scintillation use, sesquioxides can be used un-doped as intrinsic scintillators based on self-trapped excitons (e.g. $\mathrm{Lu}_{2} \mathrm{O}_{3}$ ) or ligand-to-metal charge transfer (e.g. $\mathrm{Y}_{2} \mathrm{O}_{3}$ and $\mathrm{Sc}_{2} \mathrm{O}_{3}$ ) [8]. However, doping with a luminescent activator enables sesquioxides to act as either scintillators with activator-dependent tuneable emission or luminophores in LED technology.
Because of similarities in ionic radii with RE ions and its general chemical and radiation stability, $\mathrm{Y}_{2} \mathrm{O}_{3}$ presents a suitable host for doping with RE-elements without influencing its crystal structure [9-14]. Yttrium oxide $\left(\mathrm{Y}_{2} \mathrm{O}_{3}\right)$ exhibits predominantly body-centred cubic structure; however, other $\mathrm{Y}_{2} \mathrm{O}_{3}$ phases have been also reported under different external conditions $[15,16]$. Because only the cubic phase is optically isotropic, other $\mathrm{Y}_{2} \mathrm{O}_{3}$ phases are usually of no importance for optics studies. In the cubic $\mathrm{Y}_{2} \mathrm{O}_{3}$, there are two different cationic sites occupied by $\mathrm{Y}^{3+}$ (or $\mathrm{RE}^{3+}$ ) cations having either $\mathrm{C}_{2}$ or $\mathrm{C}_{3 \mathrm{i}}\left(\mathrm{S}_{6}\right)$ local symmetries. The inversion symmetry of the latter site leads to significantly lower cross sections for ions implemented on this site compared to those on $\mathrm{C}_{2}$ sites, therefore optical properties of doped $\mathrm{Y}_{2} \mathrm{O}_{3}$ are dominated by dopant ions on $\mathrm{C}_{2}$ sites. The both crystallographic sites are adopted by dopants randomly; nevertheless, works describing the occupation of a particular site have been published too [17-19].

However, the high melting temperature of $\mathrm{Y}_{2} \mathrm{O}_{3}$ $\left(2410^{\circ} \mathrm{C}\right.$ [15]) limits its production in the form of single crystals. Highly transparent polycrystalline $\mathrm{Y}_{2} \mathrm{O}_{3}$ samples can be synthetized by vacuum or spark-plasma sintering [20, 21]. Pure or RE-doped $\mathrm{Y}_{2} \mathrm{O}_{3}$ nanopowders have been synthetized by e.g. co-precipitation [22], 
the decomposition of an yttrium complex [23] and a combustion synthesis [24]. Thin films were deposited by physical vapour deposition [25] or a sol-gel method [26]. However, to our best knowledge, not all variations of RE-doped $\mathrm{Y}_{2} \mathrm{O}_{3}$ were prepared by the sol-gel method specifically and even less were studied in the form of thin films. Sol-gel methods are a versatile and effective alternative when the goal is to test new materials of varying compositions. Also since it is not possible to prepare thin films from a melt, these high-quality thin films could find a great use in applications such as X-ray imaging.

Here, we present the sol-gel preparation (a method based on the Pechini method) of $\mathrm{Eu}^{3+}, \mathrm{Pr}^{3+}, \mathrm{Dy}^{3+}$ and $\mathrm{Tb}^{3+}$ doped $\mathrm{Y}_{2} \mathrm{O}_{3}$ in the form of bulk ceramics. All these materials were studied in terms of their scintillating and photoluminescent properties. The microstructure of the prepared samples is demonstrated by images from scanning electron microscopy. To the best of our knowledge, the sol-gel preparation of dysprosium-doped $\mathrm{Y}_{2} \mathrm{O}_{3}$ is presented here for the first time and the radioluminescence behaviour of $\mathrm{Tb}^{3+}$ or $\mathrm{Dy}^{3+}$ doped $\mathrm{Y}_{2} \mathrm{O}_{3}$ has not been published as well.

\section{EXPERIMENTAL}

\section{Bulk samples preparation}

Yttrium oxide (Crytur Turnov; $99.99 \%$ (REO)) was first dissolved in $\mathrm{HNO}_{3}$ (Penta; $65 \%$ ) in a molar ratio of $1 \mathrm{~mol} \mathrm{Y}: 3.5 \mathrm{~mol} \mathrm{HNO}_{3}$. Before use, concentrated $\mathrm{HNO}_{3}$ was diluted with water $(1: 2)$. The mixture was stirred at $60^{\circ} \mathrm{C}$ until a clear solution was obtained. Individual dopants in the form of an acetate salt, i.e. $\mathrm{RE}\left(\mathrm{CH}_{3} \mathrm{COO}\right)_{3}$ $\sim \mathrm{RE}(\mathrm{ac})_{3}(\mathrm{RE}=\mathrm{Eu}, \mathrm{Dy}, \mathrm{Pr}, \mathrm{Tb})$, were added to the $\mathrm{Y}\left(\mathrm{NO}_{3}\right)_{3}$ solution. $\mathrm{RE}^{3+}$ concentration was 5 at. $\%$ for all of the dopants used, except for $\operatorname{Pr}^{3+}$ which was prepared in 0.15 at. $\%$ concentration. $\operatorname{Eu}(\mathrm{ac})_{3}, \mathrm{Dy}(\mathrm{ac})_{3}$ and $\operatorname{Pr}(\mathrm{ac})_{3}$ were supplied from Strem Chemicals, while $\mathrm{Tb}(\mathrm{ac})_{3}$ was supplied from Alfa Aesar (all being of $99.9 \%$ (REO) purity). Because all acetates were in the form of undefined hydrates, they were dehydrated before use (the temperature of dehydration was based on literature data [27-30] and confirmed by our own STA measurement not presented here). After acetates were dissolved, citric acid (CA; Lach:ner; anhydrous; p.a.) was added to the solution with additional water to achieve a saturated solution of CA. The molar ratio of metal cations:CA was 1:4. Ethylene glycol (EG; Penta; $99 \%$ ) was added to the solution with a molar ratio of of 1:16 (metal cations:EG). The resulting solution was stirred at $80^{\circ} \mathrm{C}$ until water was evaporated. Temperature was further increased to initiate polycondensation leading up to gelation. Asprepared gel was dried at $250^{\circ} \mathrm{C}$ in air for two hours Dried xerogel was then subjected to a series of thermal treatments $-500^{\circ} \mathrm{C} / 2$ hours, $900^{\circ} \mathrm{C} / 2$ hours and the last one at $1000^{\circ} \mathrm{C}$ for 4 hours. Before the last heat treatment step, samples were uniaxially pressed into pellets.
Characterization methods

X-ray powder diffraction (XRD) data were collected at room temperature with AXS D2 Phaser (Bruker) powder diffractometer with parafocusing Bragg-Brentano geometry using $\mathrm{CoK}_{\alpha}$ radiation. Data evaluation was performed in the HighScore Plus software package (PANalytical). Scanning electron microscopy (SEM) was performed using Lyra3 GMU FIB-SEM equipment (Tescan). SEM pictures were taken in a secondary electrons mode after the samples were coated with $5 \mathrm{~nm}$ of gold.

The steady-state photoluminescence properties of the prepared samples were measured on a Fluorolog ${ }^{\mathbb{R}}-3$ Extreme spectrometer (HORIBA Jobin Yvon) using the FluorEssence ${ }^{\mathrm{TM}} 3$ software. The excitation and emission spectra were collected at room temperature with the range depending on a sample (generally, in a range of $250-800 \mathrm{~nm}$ ) with an increment of $1 \mathrm{~nm}$ and $0.5 \mathrm{~nm}$, respectively. A photomultiplier tube (PMT) with thermoelectric cooling and a Ce:InGaAs photocathode (model number R955, detection range 185 - $900 \mathrm{~nm}$ ) were used. Sample excitation was performed using a $450 \mathrm{~W}$ xenon continuous-wave (CW) lamp. To select various wavelengths, a double-diffraction-grating monochromator at the entrance and a single-diffractiongrating monochromator at the exit were used. The photoluminescence spectra were collected in a reflective arrangement with the sample being tilted at angle of approx. $60^{\circ}$. The photoluminescence radiation was collected at the front-facing exit. For the spectra evaluation, all of the measured luminescence spectra were transformed to the base level and, after subtraction of the background, normalised with the help of the reference sample (a single crystal of Ce:YAG).

The radioluminescence spectra were measured at room temperature. The custom made a $5000 \mathrm{M}$ fluorescence spectrometer (Horiba Jobin Yvon) with a TBX-04 photon counting detector (IBH Scotland) was used in all measurements. The samples were excited by an X-ray (40 kV, $15 \mathrm{~mA})$ tube (SeifertGmbh). All spectra were corrected for the spectral distortions due to the setup. Spectral resolution used in the radioluminescence spectra measurements was $8 \mathrm{~nm}$.

\section{RESULTS AND DISCUSSION}

The bulk samples were doped by four selected dopants in concentration based on the results published previously -5 at. $\%$ for $\mathrm{Eu}^{3+}, \mathrm{Dy}^{3+}, \mathrm{Tb}^{3+}$ and or 0.15 at. $\%$ for $\operatorname{Pr}^{3+}\left(\operatorname{Pr}^{3+}\right.$ ions are very sensitive to non-radiative transitions and charge transfer from $\mathrm{Pr}^{3+}$ to $\mathrm{O}^{2-}$ ). The phase composition was evaluated by XRD - all prepared samples were single phase and matched the bixbyitetype $\mathrm{Y}_{2} \mathrm{O}_{3}$ phase pattern (space group Ia-3). The change in the lattice parameter with $\mathrm{Y}$ substitution was refined 
after the XRD patterns were fitted using the Pawley profile function. The systematic increase of the lattice parameter $a$ (Tab. 1) from $10.6040 \AA$ (un-doped $\mathrm{Y}_{2} \mathrm{O}_{3}$ phase, PDF 00-041-1105) correlates with the increase of dopants' ionic radii [31]. The increase in the case of $\mathrm{Pr}^{3+}: \mathrm{Y}_{2} \mathrm{O}_{3}$ is not so high because of different concentration of $\operatorname{Pr}$ (only 0.15 at. \% in comparison with 5 at. \% for other dopants). The representative diffraction pattern (Eu: $\mathrm{Y}_{2} \mathrm{O}_{3}$ sample) indexed according to PDF 00-0411105 is shown in Figure 1.

The microstructure of prepared polycrystalline samples is demonstrated in SEM images (Figure 2) that were taken from a fracture face. It is visible that conglomerates are sintered from round particles with a size in a range of $50-150 \mathrm{~nm}$.

The RE-doped $\mathrm{Y}_{2} \mathrm{O}_{3}$ is potentially applicable as a luminophore in the green-yellow-orange-red spectral range. Due to its high melting temperature, it would be more likely used only in a polycrystalline form. Therefore, it is crucial to ensure homogeneous distribution of dopants without concentration segregation on grain boundaries that could cause concentration quenching. The luminescence properties of prepared samples were tested - the excitation and emission spectra for all samples are shown in Figure 2. Because of the second harmonic generation, the spectra measurement was interrupted in different intervals that are stated in particular figures. The excitation spectra were measured for the most intense emission wavelength published in literature, whereas the emission spectra were excited using those maxima obtained from the excitation spectra.

The excitation of the $\mathrm{Dy}^{3+}: \mathrm{Y}_{2} \mathrm{O}_{3}$ sample was tested for an emission wavelength of $573 \mathrm{~nm}$ (Figure 2a). The spectrum consisted of particular transitions from the ${ }^{6} \mathrm{H}_{15 / 2}$ ground state level (charge transfer excitation pla-ced at around $220 \mathrm{~nm}$ was not measured because of instrumental limitation). The emission spectrum was then excited using the most intense wavelength measured $-348 \mathrm{~nm}$. The structure of the spectrum indicates that $\mathrm{Dy}^{3+}$ ions occupied rather the $\mathrm{C}_{2}$ inversion-less crystal position connected with a hypersensitive electric dipole (ED) transition from the ${ }^{4} \mathrm{~F}_{9 / 2}$ level to the ${ }^{6} \mathrm{H}_{13 / 2}$ level with a maximum of $573 \mathrm{~nm}[24,32]$. Less sensitive transitions ${ }^{4} \mathrm{~F}_{9 / 2} \rightarrow{ }^{6} \mathrm{H}_{15 / 2}$ and ${ }^{4} \mathrm{~F}_{9 / 2} \rightarrow{ }^{6} \mathrm{H}_{11 / 2}$ are placed in an interval of $475-495 \mathrm{~nm}$ and at around $665 \mathrm{~nm}$, respectively.

In the excitation spectrum of the $\mathrm{Tb}^{3+}: \mathrm{Y}_{2} \mathrm{O}_{3}$ sample (Figure 2b), a spin-allowed 4f-5d transition was dominating as a band with two local maxima at 265 and $302 \mathrm{~nm}$, the second of which was chosen as an excitation

Table 1. The ionic radii of $\mathrm{Y}^{3+}$ and doped ions (for a coordination number of 6); the unit cell parameter of un-doped $\mathrm{Y}_{2} \mathrm{O}_{3}$ and the refined unit cell parameters of doped $\mathrm{RE}^{3+}: \mathrm{Y}_{2} \mathrm{O}_{3}$.

\begin{tabular}{lccccc}
\hline & $\mathrm{Y}_{2} \mathrm{O}_{3}$ & $\mathrm{Dy}^{3+}: \mathrm{Y}_{2} \mathrm{O}_{3}$ & $\mathrm{~Tb}^{3+}: \mathrm{Y}_{2} \mathrm{O}_{3}$ & $\mathrm{Eu}^{3+}: \mathrm{Y}_{2} \mathrm{O}_{3}$ & $\mathrm{Pr}^{3+}: \mathrm{Y}_{2} \mathrm{O}_{3}$ \\
\hline ionic radius $\mathrm{CN}=6$ & $\mathrm{r}\left(\mathrm{Y}^{3+}\right)=0.90 \AA$ & $\mathrm{r}\left(\mathrm{Dy}^{3+}\right)=0.91 \AA$ & $\mathrm{r}\left(\mathrm{Tb}^{3+}\right)=0.92 \AA$ & $\mathrm{r}\left(\mathrm{Eu}^{3+}\right)=0.95 \AA$ & $\mathrm{r}\left(\mathrm{Pr}^{3+}\right)=0.99 \AA$ \\
lattice parameter $(\AA)$ & 10.6040 & $10.6063(6)$ & $10.6103(2)$ & $10.6240(4)$ & $10.6059(1)$ \\
\hline
\end{tabular}

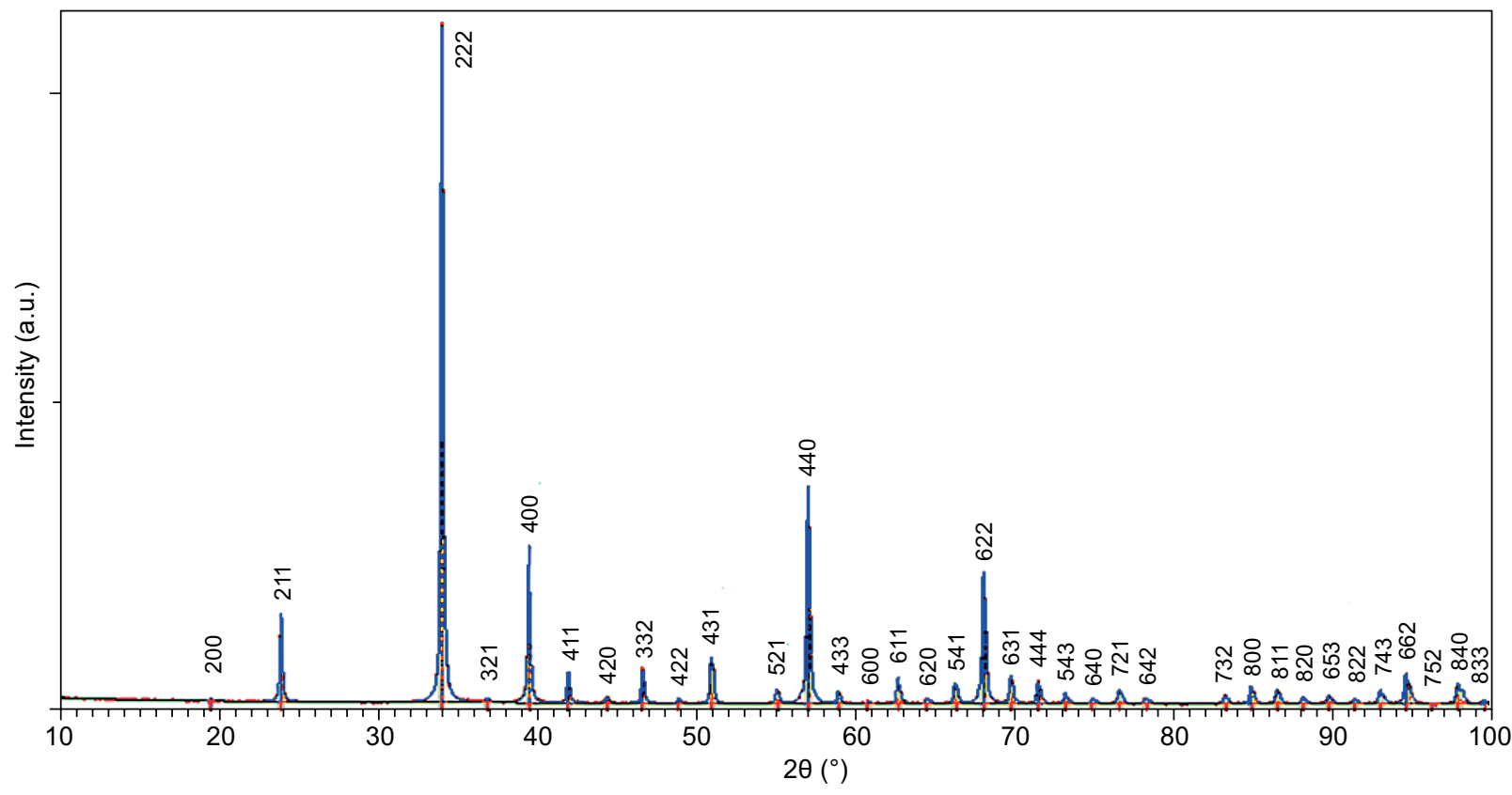

Figure 1. The XRD pattern of sample Eu: $\mathrm{Y}_{2} \mathrm{O}_{3}$ indexed according to PDF 00-041-1105. The difference plot of the Pawley profile fit is also shown. 


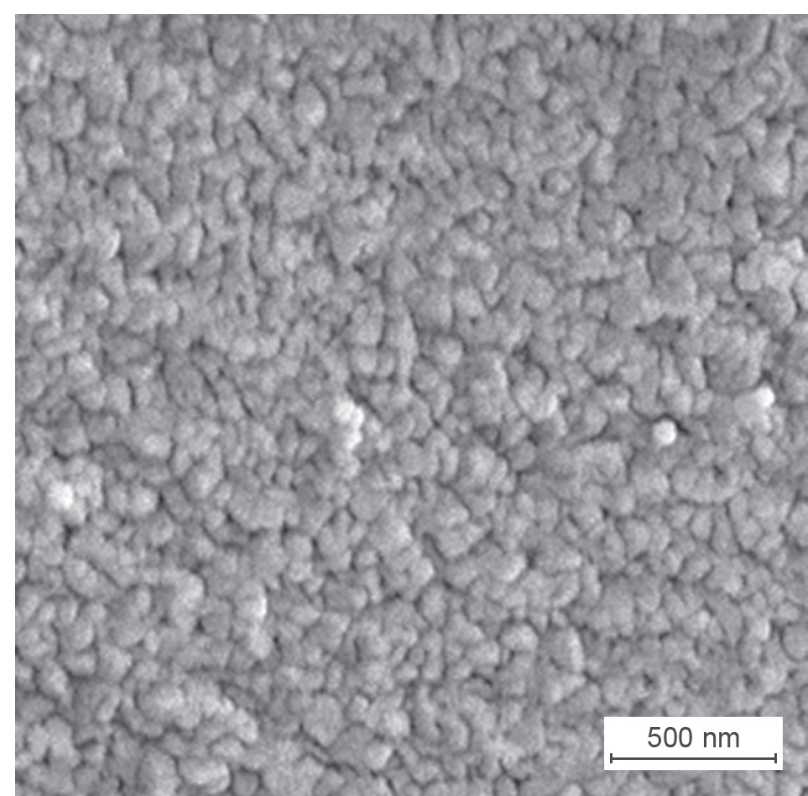

a) $\mathrm{Dy}^{3+}$

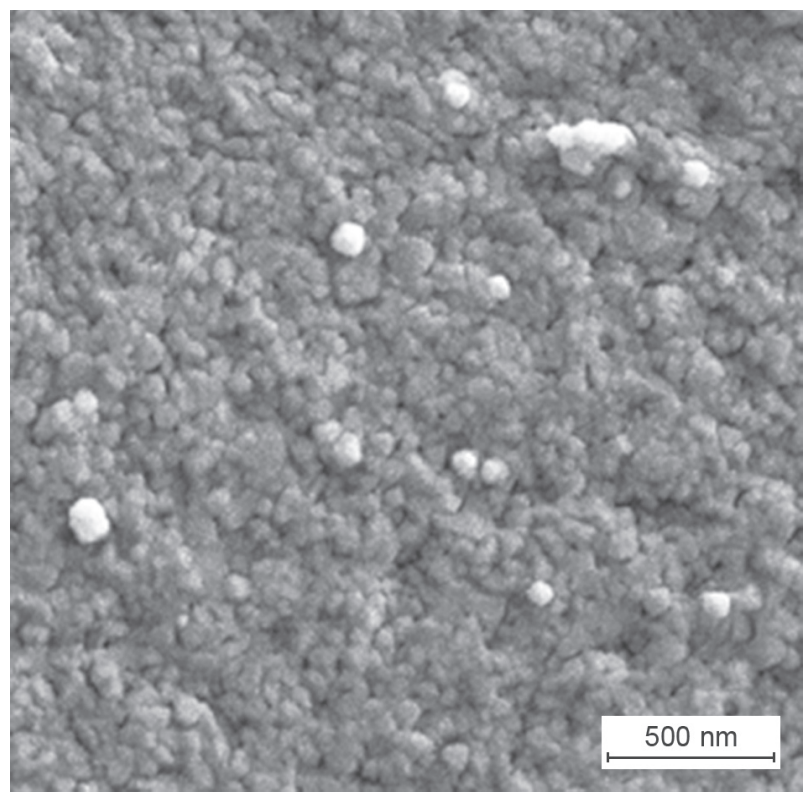

c) $\mathrm{Eu}^{3+}$

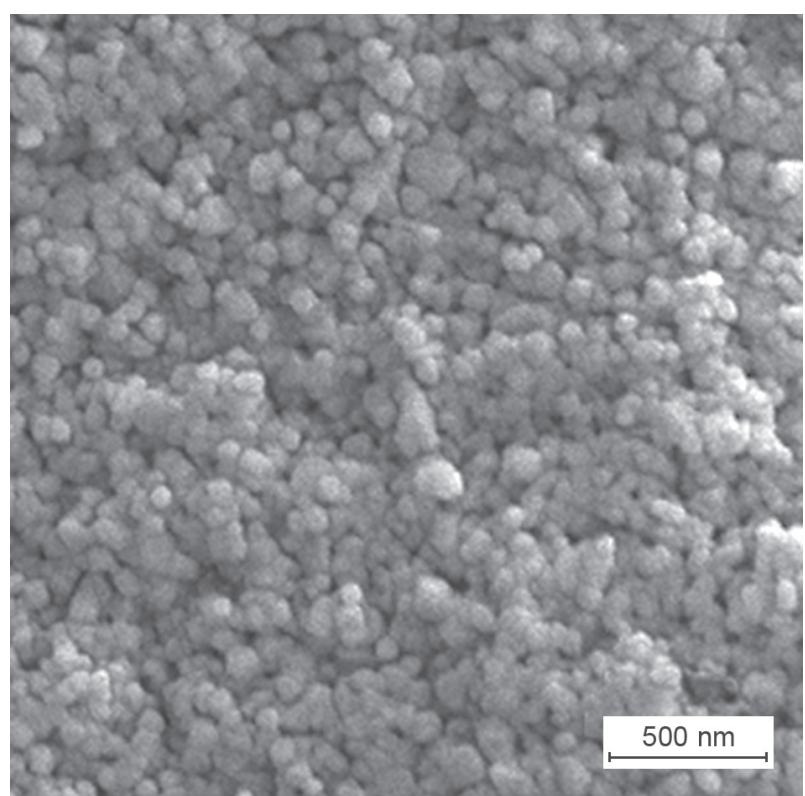

b) $\mathrm{Tb}^{3+}$

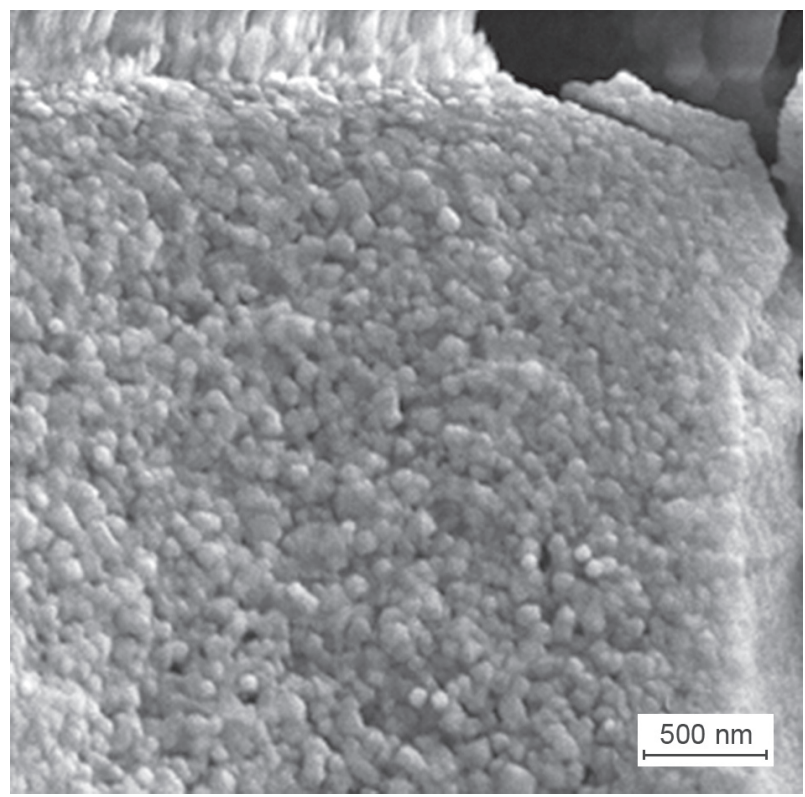

d) $\operatorname{Pr}^{3+}$

Figure 2. SEM images of prepared polycrystalline samples. The magnification of images is approx. $110000 \times$; the precise scale is given in individual images: a) $\mathrm{Dy}^{3+}$, b) $\mathrm{Tb}^{3+}$, c) $\mathrm{Eu}^{3+}$, d) $\mathrm{Pr}^{3+}$.

wavelength. The emission of $\mathrm{Tb}^{3+}$ ions exhibited four finely split bands corresponding to the ${ }^{5} \mathrm{D}_{4} \rightarrow{ }^{7} \mathrm{~F}_{J}$ transitions $(J=3,4,5$ and 6$)$. The most intense band in an interval of $538-557 \mathrm{~nm}$ with a local maximum of $543 \mathrm{~nm}$ belongs to the ${ }^{5} \mathrm{D}_{4} \rightarrow{ }^{7} \mathrm{~F}_{5}$ transition and is considered to be of mixed electric dipole (ED) and magnetic dipole (MD) nature [32]. The less intense bands are placed around local maxima of 486, 583 and $622 \mathrm{~nm}$.

In the excitation spectrum of the $\mathrm{Eu}^{3+}: \mathrm{Y}_{2} \mathrm{O}_{3}$ sample (Figure 3c), a spin-allowed charge transfer transition from $2 \mathrm{p}$ orbitals $\left(\mathrm{O}^{2-}\right)$ to $4 \mathrm{f}$ orbitals $\left(\mathrm{Eu}^{3+}\right)$ was present. Also f-f transitions from the ${ }^{7} \mathrm{~F}_{0}$ ground level are spread over an interval of 318 - $538 \mathrm{~nm}$. For the emission spectrum measurement, the excitation via the charge transfer $(259 \mathrm{~nm})$ was chosen. The emis-sion spectrum is composed of individual ${ }^{5} \mathrm{D}_{0} \rightarrow{ }^{7} \mathrm{~F}_{J}(J=0,1,2,3,4)$ transitions. The most intense one - with a ma-ximum of $612 \mathrm{~nm}$ - belongs to a hypersensitive electric dipole (ED) transition from the ${ }^{5} \mathrm{D}_{0}$ level to the ${ }^{7} \mathrm{~F}_{2}$ level [12].

The excitation of the $\operatorname{Pr}^{3+}: \mathrm{Y}_{2} \mathrm{O}_{3}$ sample was tested for an emission wavelength of $634 \mathrm{~nm}$ (Figure 2d). Two absorptions can be recognized - the most intense one belonging to a spin allowed $4 \mathrm{f}-5 \mathrm{~d}$ transition of $\mathrm{Pr}^{3+}$ ions with a maximum of $277 \mathrm{~nm}$ and less intense one of $\mathrm{f}-\mathrm{f}$ 
excitation from the ${ }^{3} \mathrm{H}_{4}$ ground state to excited states (in an interval of $450-500 \mathrm{~nm}$ ). In the emission spectrum, two transitions can be identified. The transition from the ${ }^{1} \mathrm{D}_{2}$ excited level to the ${ }^{3} \mathrm{H}_{4}$ ground state with several

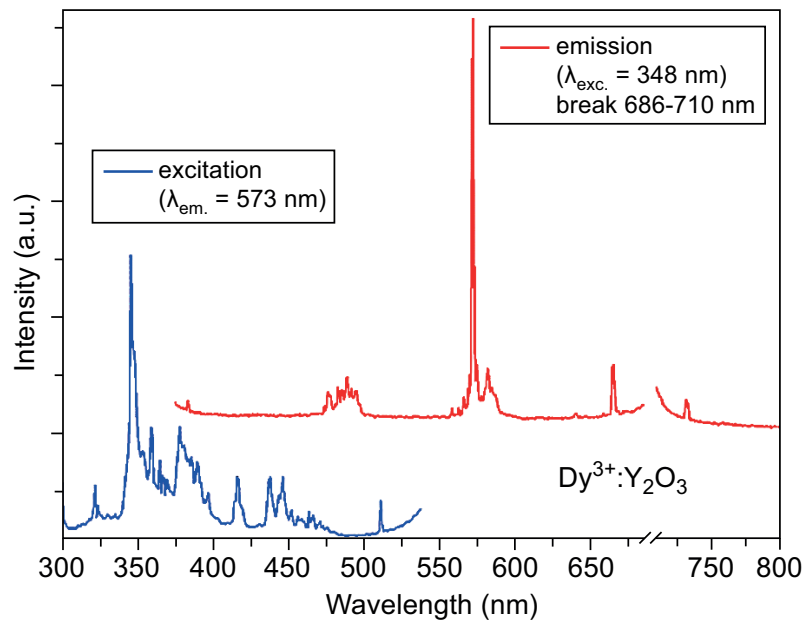

a)

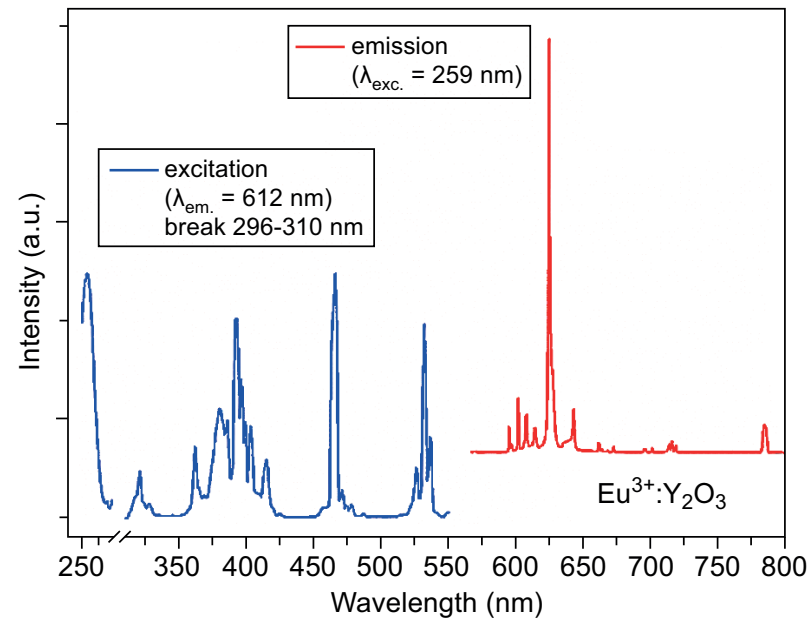

c) local maxima ( $630 \mathrm{~nm}$ being the most intense) is located in an interval of $615-660 \mathrm{~nm}$. Much weaker emission (belonging to the ${ }^{1} \mathrm{D}_{2} \rightarrow{ }^{3} \mathrm{H}_{5}$ and ${ }^{1} \mathrm{D}_{2} \rightarrow{ }^{3} \mathrm{~F}_{3,4}$ transitions) can be seen in an interval of $705-750 \mathrm{~nm}$. In summary,

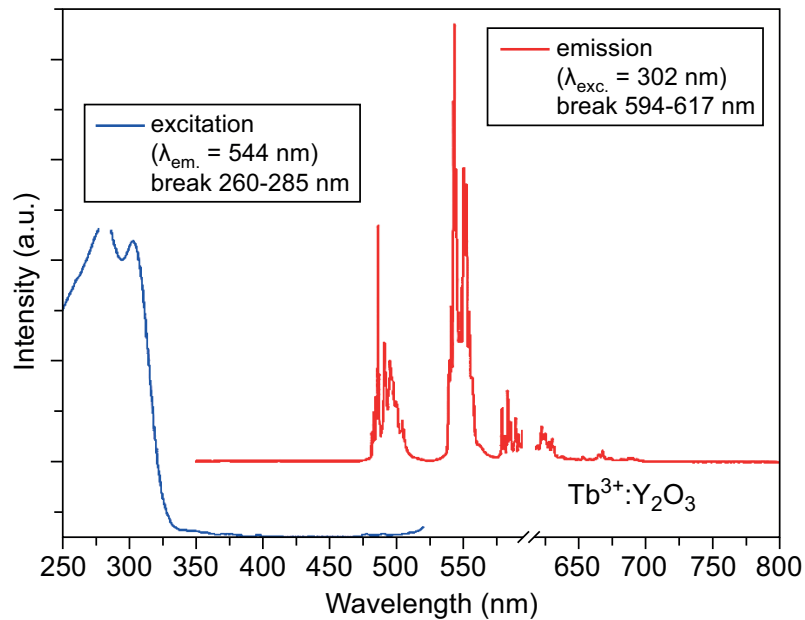

b)

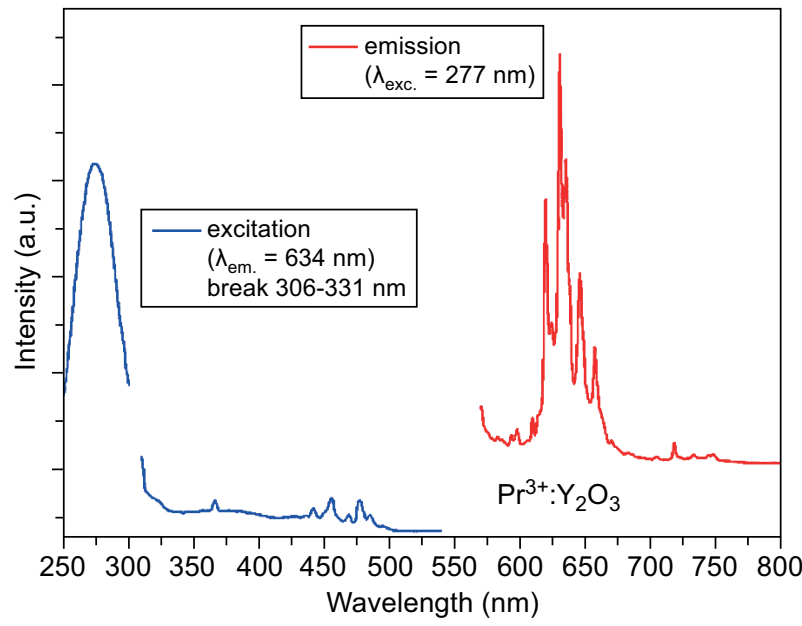

d)

Figure 3. Excitation and emission spectra (blue and red lines, respectively) of: a) $\mathrm{Dy}^{3+}$, b) $\mathrm{Tb}^{3+}$, c) $\mathrm{Eu}^{3+}$, d) $\mathrm{Pr}^{3+}$ doped $\mathrm{Y}_{2} \mathrm{O}_{3}$ polycrystalline samples.

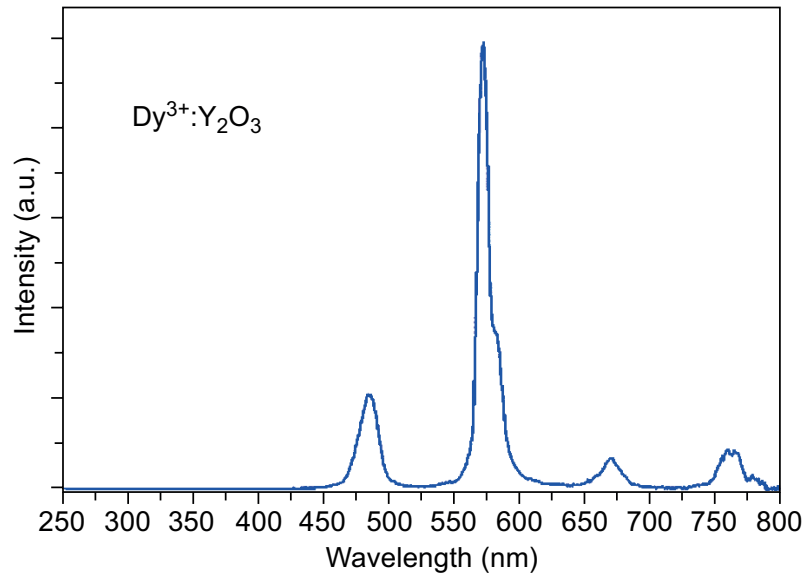

a)

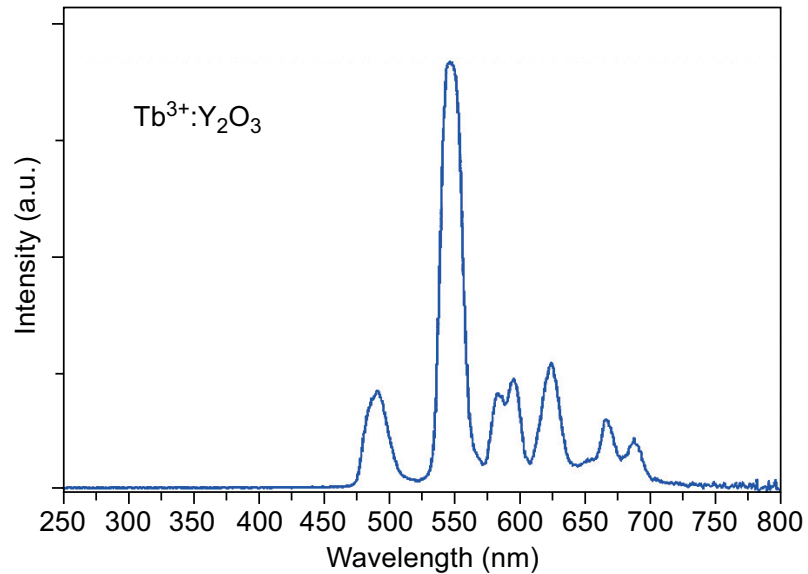

b)

Figure 4. Radioluminescence spectra of $\mathrm{Y}_{2} \mathrm{O}_{3}$ polycrystalline samples doped with: a) $\left.\mathrm{Dy}^{3+}, \mathrm{b}\right) \mathrm{Tb}^{3+}$. (Continue on next page) 


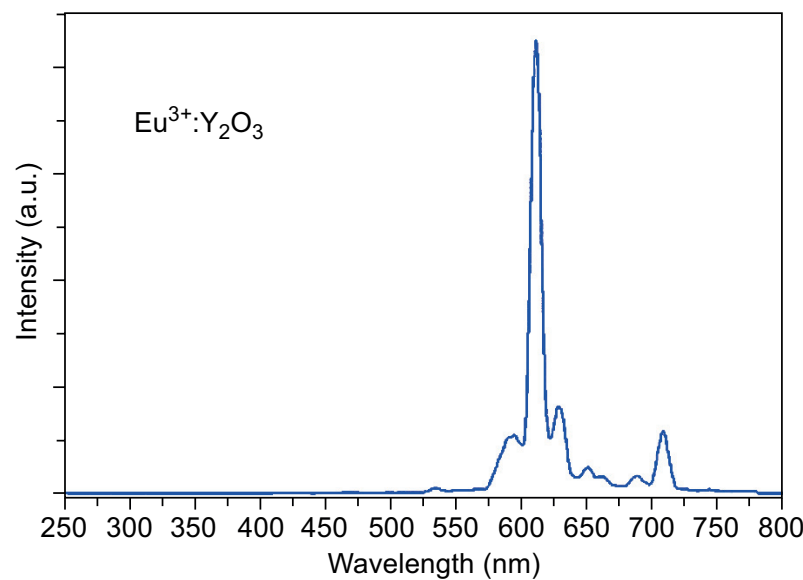

c)

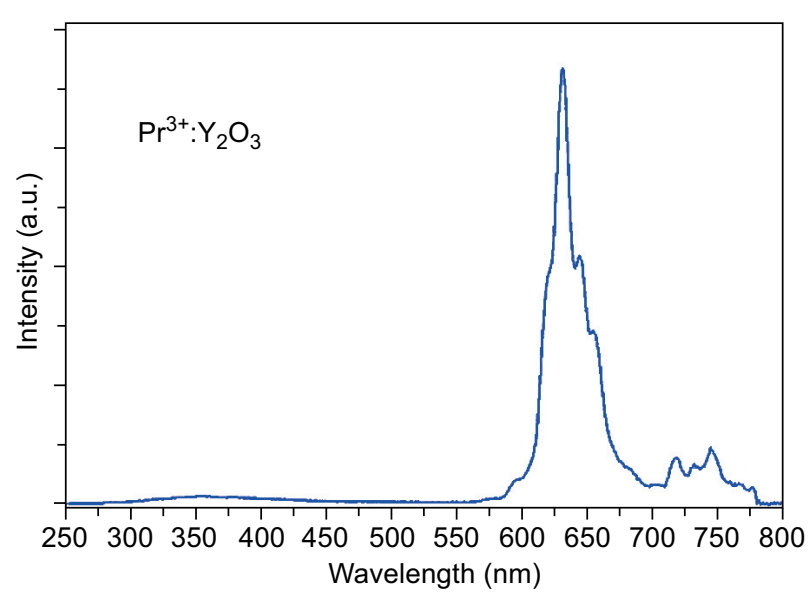

d)

Figure 4. Radioluminescence spectra of $\mathrm{Y}_{2} \mathrm{O}_{3}$ polycrystalline samples doped with: c) $\mathrm{Eu}^{3+}$, d) $\mathrm{Pr}^{3+}$.

the measured photoluminescence spectra of all doped $\mathrm{Y}_{2} \mathrm{O}_{3}$ samples exhibiting narrow and finely separated emissions bands confirmed good crystallinity with cations having regular crystal vicinity.

Because of crystal structure stability, isotropic behaviour, wide band gap and other properties, $\mathrm{Y}_{2} \mathrm{O}_{3}$ is suitable matrix not only for lasers or luminophores but also for scintillation use (e.g. for X-ray detection). Radioluminescence spectra excited by X-ray measured at room temperature are presented in Figure 4. The general structure of the emission spectra is very similar to those of photoluminescence emission, including the positions of local maxima. The emission bands are not so well separated (this effect is caused by the lower spectral resolution of an instrumental setting); however, the measured spectra verify that the used synthesis method and chosen dopant concentrations are suitable for the application in X-ray detection field. The polycrystalline nature of samples did not negatively influence the complicated multi-step mechanism of scintillation and did not suppress the light output.

\section{CONCLUSION}

We present the sol-gel preparation of lanthanidedoped $\mathrm{Y}_{2} \mathrm{O}_{3}$ applicable either as a luminophore or a scintillation material. $\mathrm{Dy}^{3+}, \mathrm{Tb}^{3+}, \mathrm{Eu}^{3+}$ and $\mathrm{Pr}^{3+}$ doped bulk samples were synthetized using a Pechini-based sol-gel method. Using XRD, we evaluated single phase composition of the prepared samples and the change of unit cell parameter with the doping was determined. The optical properties of the doped $\mathrm{Y}_{2} \mathrm{O}_{3}$ were evaluated by photoluminescence and radioluminescence measurement. The photoluminescence spectra were excited with a wavelength first evaluated by excitation spectra measurement. Observed emission spectra proved good samples crystallinity with cations having regular crystal vicinity what was demonstrated by narrow and finely separated emission bands. Also radioluminescence spectra excited by X-ray showed that prepared ceramics is applicable as a scintillator in a yellow-orange-red spectral range. The used sol-gel method is suitable for the production of bulk sesquioxides that have a melting temperature so high that the preparation of monocrystalline samples is complicated.

\section{Acknowledgements}

This work was financially supported by specific university research (MSMT No 21-SVV/2018) and by the TACR, project No. TJ0100411.

\section{REFERENCES}

1. Kaminskii A.A. (2007): Laser crystals and ceramics: recent advances. Laser \& Photonics Reviews, 1, 93-177. doi: 10.1002/lpor.200710008

2. Lakeman C.D.E., Payne D.A. (1994): Sol-gel processing of electrical and magnetic ceramics. Materials Chemistry and Physics, 38, 305-324. doi: 10.1016/0254-0584(94)90207-0

3. von Wenckstern H. (2017): Group-III Sesquioxides: Growth, Physical Properties and Devices. Advanced Electronic Materials, 3, doi: 10.1002/aelm.201600350

4. Grygar T., Bezdicka P., Dedecek J., Petrovsky E., Schneeweiss O. (2003): $\mathrm{Fe}_{2} \mathrm{O}_{3}-\mathrm{Cr}_{2} \mathrm{O}_{3}$ system revised. CeramicsSilikaty, 47, 32-39.

5. Rosynek M.P. (1977): Catalytic Properties of Rare Earth Oxides. Catalysis Reviews, 16, 111-154. doi: 10.1080/ 03602457708079635

6. Xie G.Q., Tang D.Y., Zhao L.M., Qian L.J., Ueda K. (2007): High-power self-mode-locked $\mathrm{Yb}: \mathrm{Y}_{2} \mathrm{O}_{3}$ ceramic laser. Opt. Lett., 32, 2741-2743. doi: 10.1364/OL.32.002741

7. Salek G., Devoti A., Garcia A., Gaudon M., Jubera V., Demourgues A. (2016): Tuning the composition of rare earth sesquioxides $\mathrm{Gd}^{2}{ }_{x} \mathrm{LaxO}_{3}: \mathrm{Eu}^{3+}$ to control phase transitions at a high temperature to design new highly sensitive luminescence-based thermal sensors. RSC Advances, 6, 55298-55306. doi: 10.1039/C6RA07607F

8. Blasse G., Brixner L.H. (1991): The nature of the lumi- 
nescence of $\mathrm{Y}_{2} \mathrm{O}_{3}$ and $\mathrm{Sc}_{2} \mathrm{O}_{3}$. European Journal of Solid State and Inorganic Chemistry, 28, 767-771.

9. Atabaev T.S., Vu H.H.T., Kim H.-K., Hwang Y.-H. (2012): Synthesis and optical properties of $\mathrm{Dy}^{3+}$-doped $\mathrm{Y}_{2} \mathrm{O}_{3}$ nanoparticles. Journal of the Korean Physical Society, 60, 244-248. doi: $10.3938 / \mathrm{jkps} .60 .244$

10. Balderas-Xicohténcatl R., Martínez-Martínez R., RiveraAlvarez Z., Santoyo-Salazar J., Falcony C. (2014): Photo and cathodoluminescence characteristics of dysprosium doped yttrium oxide nanoparticles prepared by Polyol method. Journal of Luminescence, 146, 497-501. doi: 10.1016/ j.jlumin.2013.10.041

11. Dudek M., Jusza A., Anders K., Lipińska L., Baran M., Piramidowicz R. (2011): Luminescent properties of praseodymium doped $\mathrm{Y}_{2} \mathrm{O}_{3}$ and $\mathrm{LaAlO}_{3}$ nanocrystallites and polymer composites. Journal of Rare Earths, 29, 1123-1129. doi: 10.1016/S1002-0721(10)60610-2

12. Kumar Y., Pal M., Herrera M., Mathew X. (2016): Effect of $\mathrm{Eu}$ ion incorporation on the emission behavior of $\mathrm{Y}_{2} \mathrm{O}_{3}$ nanophosphors: A detailed study of structural and optical properties. Optical Materials, 60, 159-168. doi: 10.1016/j. optmat.2016.07.026

13. Ramírez A.d.J.M., Murillo A.G., Romo F.d.J.C., Hernández M.G., Rosa E.d.1., Palmerin J.M. (2011): $\mathrm{Y}_{2} \mathrm{O}_{3}: \mathrm{Eu}^{3+}, \mathrm{Tb}^{3+}$ thin films prepared by sol-gel method: structural and optical studies. Journal of Sol-Gel Science and Technology, 58, 366-373. doi: 10.1007/s10971-011-2402-2

14. Alarcón-Flores G., García-Hipólito M., Aguilar-Frutis M., Carmona-Téllez S., Martinez-Martinez R., Campos-Arias M.P., Zaleta-Alejandre E., Falcony C. (2015): Synthesis and fabrication of $\mathrm{Y}_{2} \mathrm{O}_{3}: \mathrm{Tb}^{3+}$ and $\mathrm{Y}_{2} \mathrm{O}_{3}: \mathrm{Eu}^{3+}$ thin films for electroluminescent applications: Optical and structural characteristics. Materials Chemistry and Physics, 149, 34-42. doi: 10.1016/j.matchemphys.2014.09.020

15. Zhang P., Navrotsky A., Guo B., Kennedy I., Clark A.N., Lesher C., Liu Q. (2008): Energetics of cubic and monoclinic yttrium oxide polymorphs: Phase transitions, surface enthalpies, and stability at the nanoscale. Journal of Physical Chemistry C, 112, 932-938. doi: 10.1021/jp7102337

16. Dilawar Sharma N., Singh J., Vijay A., Samanta K., Dogra S., Bandyopadhyay A.K. (2016): Pressure-Induced Structural Transition Trends in Nanocrystalline Rare-Earth Sesquioxides: A Raman Investigation. The Journal of Physical Chemistry C, 120, 11679-11689. doi: 10.1021/acs. jpcc.6b02104

17. Stanek C.R., McClellan K.J., Uberuaga B.P., Sickafus K.E., Levy M.R., Grimes R.W. (2007): Determining the site preference of trivalent dopants in bixbyite sesquioxides by atomic-scale simulations. Physical Review B, 75, 134101. doi: 10.1103/PhysRevB.75.134101

18. Antic B., Mitric M., Rodic D. (1997): Cation ordering in cubic and monoclinic $(\mathrm{Y}, \mathrm{Eu})_{2} \mathrm{O}_{3}$ : an X-ray powder diffraction and magnetic susceptibility study. Journal of Physics: Condensed Matter, 9, 365. doi: 10.1088/0953-8984/9/2/004

19. Kränkel C. (2015): Rare-Earth-Doped Sesquioxides for Diode-Pumped High-Power Lasers in the 1-, 2-, and 3-\&\#x03BC;m Spectral Range. IEEE Journal of Selected Topics in Quantum Electronics, 21, 250-262. doi: 10.1109/ JSTQE.2014.2346618

20. Futami Y., Yanagida T., Fujimoto Y., Pejchal J., Sugiyama
M., Kurosawa S., Yokota Y., Ito A., Yoshikawa A., Goto T. (2013): Optical and scintillation properties of $\mathrm{Sc}_{2} \mathrm{O}_{3}$, $\mathrm{Y}_{2} \mathrm{O}_{3}$ and $\mathrm{Lu}_{2} \mathrm{O}_{3}$ transparent ceramics synthesized by SPS method. Radiation Measurements, 55, 136-140. doi: https:// doi.org/10.1016/j.radmeas.2013.01.014

21. Fukabori A., Yanagida T., Pejchal J., Maeo S., Yokota Y., Yoshikawa A., Ikegami T., Moretti F., Kamada K. (2010): Optical and scintillation characteristics of $\mathrm{Y}_{2} \mathrm{O}_{3}$ transparent ceramic. Journal of Applied Physics, 107, 073501. doi: 10. $1063 / 1.3330407$

22. Kumar D., Sharma M., Haranath D., Pandey O.P. (2017): Facile route to produce spherical and highly luminescent $\mathrm{Tb}^{3+}$ doped $\mathrm{Y}_{2} \mathrm{O}_{3}$ nanophosphors. Journal of Alloys and Compounds, 695, 726-736. doi: 10.1016/j.jallcom.2016. 06.124

23. Pižl M., Jankovský O., Ulbrich P., Szabó N., Hoskovcová I., Sedmidubský D., Bartůněk V. (2017): Facile preparation of nanosized yttrium oxide by the thermal decomposition of amorphous Schiff base yttrium complex precursor. Journal of Organometallic Chemistry, 830, 146-149. doi:10.1016/j. jorganchem.2016.12.018

24. Som S., Sharma S.K., Shripathi T. (2013): Influences of Doping and Annealing on the Structural and Photoluminescence Properties of $\mathrm{Y}_{2} \mathrm{O}_{3}$ Nanophosphors. Journal of Fluorescence, 23, 439-450. doi: 10.1007/s10895-0131160-7

25. Dodson C.M., Kurvits J.A., Li D., Jiang M., Zia R. (2014): Magnetic dipole emission of $\mathrm{Dy}^{3+}: \mathrm{Y}_{2} \mathrm{O}_{3}$ and $\mathrm{Tm}^{3+}: \mathrm{Y}_{2} \mathrm{O}_{3}$ at near-infrared wavelengths. Optical Materials Express, 4, 2441-2450. doi: 10.1364/OME.4.002441

26. Rao R.P. (1996): Growth and characterization of $\mathrm{Y}_{2} \mathrm{O}_{3}: \mathrm{Eu}^{3+}$ phosphor films by sol-gel process. Solid State Communications, 99, 439-443. doi: 10.1016/0038-1098(96)00249-9

27. Balboul B.A.A., Zaki M.I. (2011): Thermal decomposition course of $\mathrm{Eu}\left(\mathrm{CH}_{3} \mathrm{COO}\right)_{3} \cdot 4 \mathrm{H}_{2} \mathrm{O}$ and the reactivity at the gas/solid interface thus established. Journal of Analytical and Applied Pyrolysis, 92, 137-142. doi: 10.1016/j.jaap. 2011.05.004

28. Soliman S.A., Abu-Zied B.M. (2009): Thermal genesis, characterization, and electrical conductivity measurements of terbium oxide catalyst obtained from terbium acetate. Thermochimica Acta, 491, 84-91. doi: 10.1016/j.tca.2009. 03.006

29. Hussein G.A.M., Kroenke W.J., Goda B., Miyaji K. (1997): Formation of dysprosium oxide from the thermal decomposition of hydrated dysprosium acetate and oxalate Thermoanalytical and microscopic studies. Journal of Analytical and Applied Pyrolysis, 39, 35-51. doi: 10.1016/ S0165-2370(96)00961-8

30. Hussein G.A.M. (1994): Formation of praseodymium oxide from the thermal decomposition of hydrated praseodymium acetate and oxalate. Journal of Analytical and Applied Pyrolysis, 29, 89-102. doi: 10.1016/0165-2370(93)00782-I

31. Shannon R. (1976): Revised effective ionic radii and systematic studies of interatomic distances in halides and chalcogenides. Acta Crystallographica Section A, 32, 751-767. doi: doi:10.1107/S0567739476001551

32. Avram D., Cojocaru B., Florea M., Tiseanu C. (2016): Advances in luminescence of lanthanide doped $\mathrm{Y}_{2} \mathrm{O}_{3}$ : case of S6 sites. Optical Materials Express, 6, 1635-1643. doi: 10.1364/OME.6.001635 